\title{
Bilateral Chylothorax and Chylous Ascites: A Rare Presentation of an Uncommon Disorder
}

\author{
Akhilesh Mahajan ${ }^{1,2}$, Pratyaksha Sankhyan 3, 2 , Boonphiphop Boonpheng 4, 2 \\ 1. Pulmonary Critical Care, Lenox Hill Hospital, New York, USA 2. Internal Medicine, East Tennessee State University, \\ Johnson City, USA 3. Pulmonary Critical Care, East Carolina University, Greenville, USA 4. Nephrology, University of \\ California Los Angeles, Los Angeles, USA
}

Corresponding author: Akhilesh Mahajan, akhileshmahajan3@gmail.com

\begin{abstract}
We describe the case of a 62-year-old female who presented with gradually progressing abdominal distension and dyspnea. Computed tomography (CT) chest and abdomen revealed large bilateral pleural effusions with large ascites, a mid-abdominal mass, and peritoneal carcinomatosis. Pleural and peritoneal tap revealed chylous fluid, and the biopsy findings from abdominal mass were consistent with follicular lymphoma. We then discuss a review of the literature and diagnoses for bilateral chylothorax and chylous ascites.
\end{abstract}

Categories: Internal Medicine, Oncology, Pulmonology

Keywords: chylothorax, chylous ascites, follicular lymphoma, peritoneal carcinomatosis

\section{Introduction}

Chylothorax and chylous ascites are both rarely encountered and often difficult-to-manage clinical entities with only a few case reports and even fewer clinical studies. Both of these are usually associated with malignancies, however, chylothorax and chylous ascites as the presentation of malignancy are rare.

Follicular lymphoma is the most common type of indolent non-Hodgkin lymphoma. It is a very slowgrowing lymphoma that generally affects the lymph nodes and may spread to the bone marrow or spleen. Patients commonly present with gradually enlarging painless peripheral lymphadenopathy and the diagnosis is usually made on a lymph node biopsy.

Received 08/08/2017 Review began 09/13/2017 Review ended 02/16/2021 Published 03/22/2021

\section{() Copyright 2021}

Mahajan et al. This is an open access article distributed under the terms of the Creative Commons Attribution License CC-BY 4.0, which permits unrestricted use, distribution, and reproduction in any medium, provided the original author and source are credited.
We describe an important presentation of this disease in a patient who had no peripheral lymphadenopathy but instead had both chylothorax and chylous ascites caused by the lymphoma, which kept growing insidiously until she presented with abdominal distension and dyspnea. Pleural and peritoneal fluid cytology and flow cytometry were negative for malignant cells and definitive diagnosis could only be obtained on fine-needle aspiration and core needle biopsy of her large mid-abdominal mass.

\section{Case Presentation}

A 62-year-old caucasian female with no significant past medical history presented to our hospital with the chief complaint of gradually progressing abdominal distension for one month and progressive dyspnea with a decreased appetite for five to seven days. She was released about two months ago from a penitentiary and had not been seen by a physician in several years. On review of systems, she denied any fever, chills, night sweats, or weight loss.

On physical examination, she was hemodynamically stable with normal oxygen saturation on room air. She had dullness to percussion in the scapular line till the inferior angle of the scapula on both sides and decreased breath sounds at both lung bases. A grossly distended abdomen with shifting dullness was also noted. She didn't have any palpable lymphadenopathy and the rest of her physical examination was normal.

Her laboratory data on admission were within normal limits with a white cell count (WCC) of $5.7 \mathrm{~K} / \mathrm{uL}$, hemoglobin of $13 \mathrm{~g} / \mathrm{dL}$, platelet count of $381 \mathrm{~K} / \mathrm{uL}$, and international normalized ratio (INR) of 1.0. Her electrolytes, liver function tests, and renal function tests were also within normal limits.

Computed tomography (CT) of the chest and abdomen with contrast revealed large bilateral pleural effusions with volume loss at the lung bases (Figure 1), large ascites with a mid-abdominal mesenteric mass, measuring $14 \mathrm{~cm} \times 9 \mathrm{~cm} \times 13 \mathrm{~cm}$, engulfing the superior mesenteric artery (Figure 2) and possible peritoneal carcinomatosis (Figure 3). Her liver, spleen, and ovaries were noted to be normal. At this point, the differentials included lymphoma versus Kruckenberg tumor versus a number of gastrointestinal tract malignancies that could present as peritoneal carcinomatosis. 


\section{Cureus}

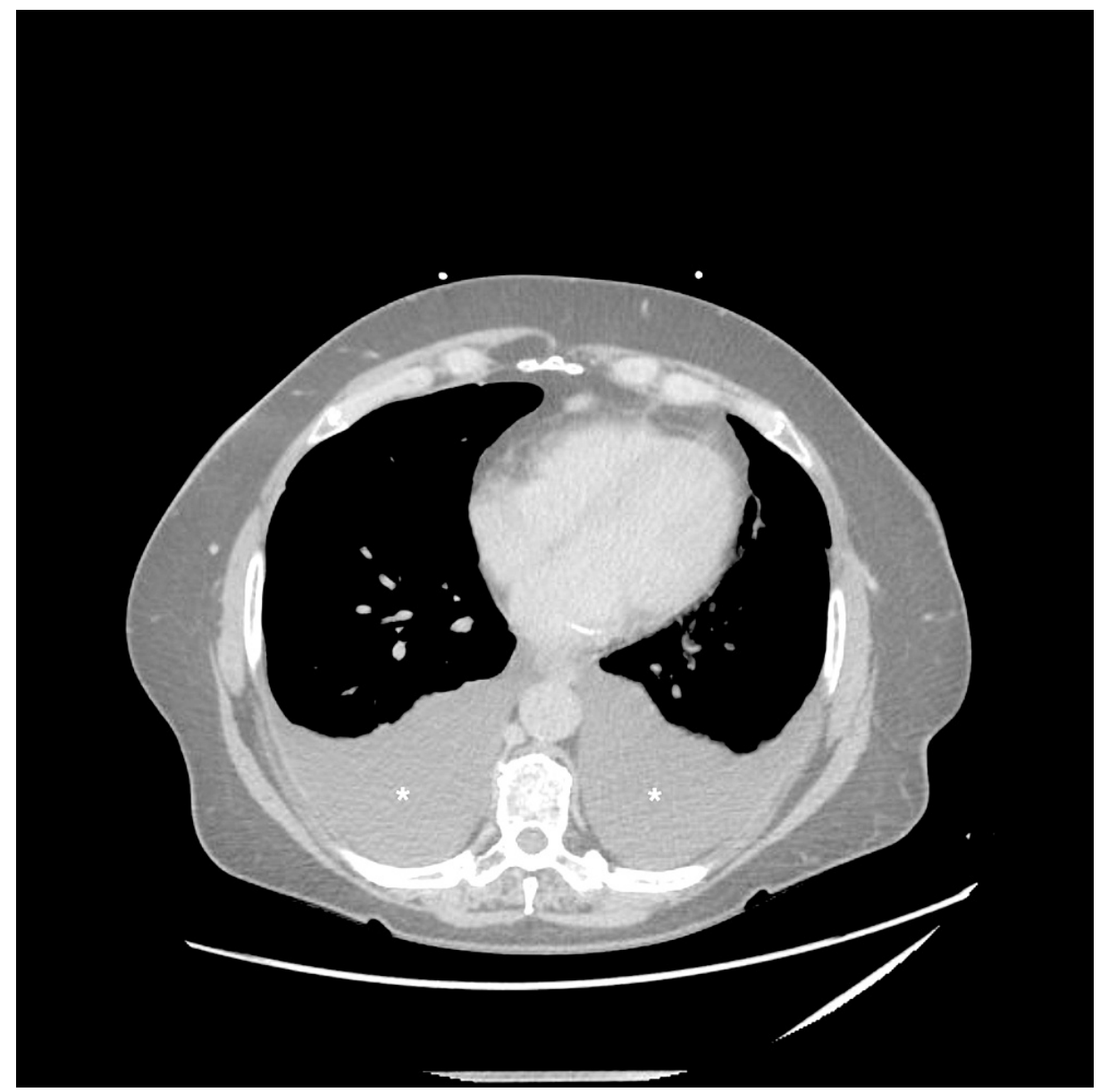

FIGURE 1: Computed tomography of chest (axial section)

CT chest demonstrates large bilateral pleural effusions (white asterisks)

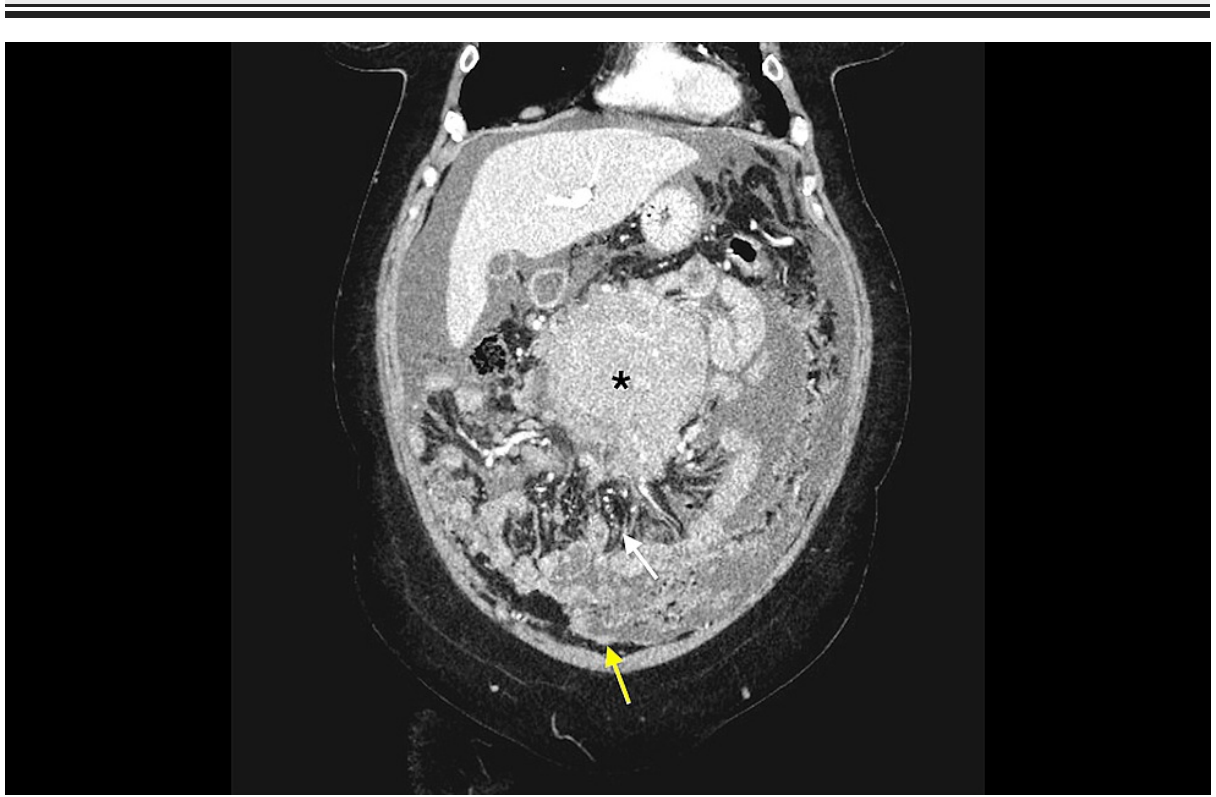

FIGURE 2: Computed tomography of the abdomen (coronal section)

CT abdomen describes a large mid-abdominal mass (black asterisk), mesenteric thickening (yellow arrow), and peritoneal thickening with stellate appearance (white arrow) suggesting peritoneal carcinomatosis. 


\section{Cureus}

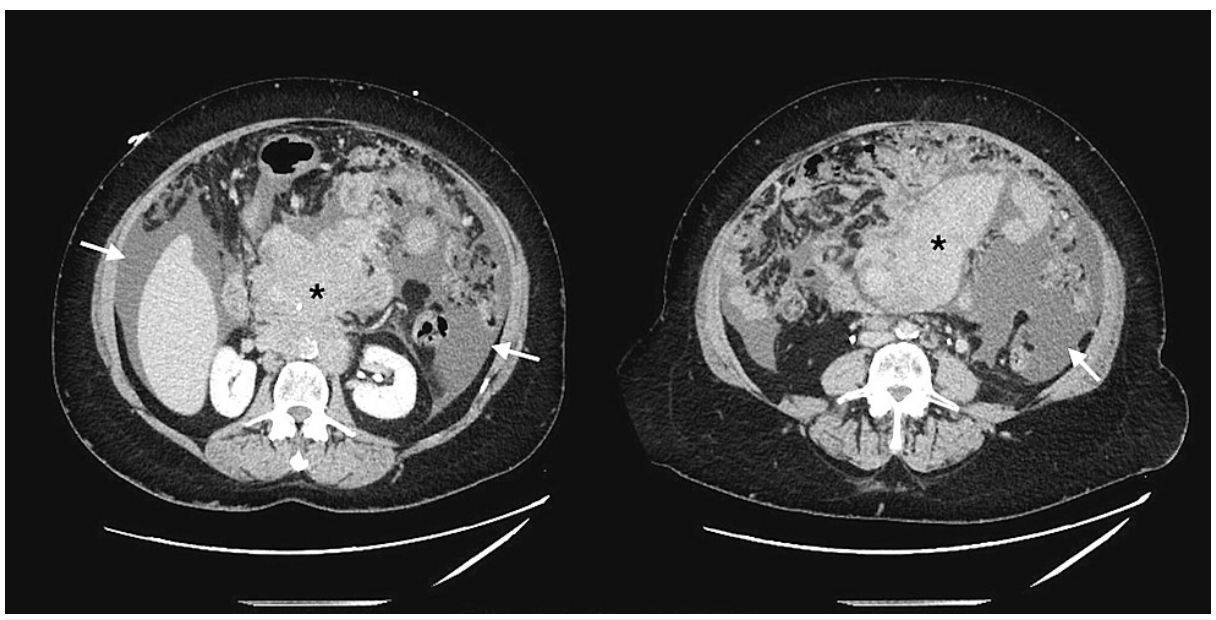

FIGURE 3: Computed tomography of the abdomen (axial section)

CT abdomen demonstrates a large midabdominal mass (black asterisks) and large ascites (white arrows).

Under aseptic precautions, ultrasound (US)-guided paracentesis and left-sided thoracentesis were performed and $1100 \mathrm{~mL}$ and $500 \mathrm{~mL}$ of cloudy white fluid were drained, respectively, with significant improvement in the patient's symptoms. The pleural and peritoneal fluid laboratory parameters have been presented in Table 1.

\begin{tabular}{|c|c|c|c|}
\hline Lab parameters & Serum & Pleural fluid & Peritoneal fluid \\
\hline Protein & $6.2 \mathrm{~g} / \mathrm{dL}$ & $4.3 \mathrm{~g} / \mathrm{dL}$ & $4.3 \mathrm{~g} / \mathrm{dL}$ \\
\hline Albumin & $3.3 \mathrm{~g} / \mathrm{dL}$ & $3.2 \mathrm{~g} / \mathrm{dL}$ & $3.1 \mathrm{~g} / \mathrm{dL}$ \\
\hline LDH & 393 U/L & $345 \mathrm{U} / \mathrm{L}$ & \\
\hline Triglycerides & & $965 \mathrm{mg} / \mathrm{dL}$ & \\
\hline Cholesterol & & 137 mg/dL & \\
\hline Glucose & 93 mg/dL & & \\
\hline WCC & & 4606 cells/uL & 2261 cells/uL \\
\hline
\end{tabular}

\section{TABLE 1: Pleural and peritoneal fluid analysis}

lactate dehydrogenase (LDH); white cell count (WCC)

On chemistry, pleural fluid was exudative in nature as per Light's criteria with an effusion-to-serum protein ratio of more than 0.5 and an effusion-to-serum lactate dehydrogenase (LDH) ratio greater than 0.6. Peritoneal fluid was also exudative in nature with serum ascites albumin gradient (SAAG) less than 1.1 $\mathrm{g} / \mathrm{dL}$. On cytology, lymphocyte predominance was seen with no malignant cells. Gram stain, acid-fast stain, and cultures were also negative. Immunophenotypic analysis of pleural and peritoneal fluid by flow cytometry showed polyclonal lymphocyte population without clonal excess and no immunoglobulin light chain restriction, aberrant antigenic expression, or antigen loss. She also had a normal CD4: CD8 ratio of 3:1 and B lymphocytes with a normal Kappa: Lambda light chain ratio of 1:2.

Despite the presence of a large intraabdominal mass, peritoneal and pleural fluid flow cytometry remained inconclusive and hence CT-guided fine-needle aspiration (FNA) and core needle biopsy were done. While awaiting the biopsy results, she was switched to a high protein and low-fat diet with medium-chain triglyceride (MCT) supplementation. Since the patient was symptomatically better and no recurrent fluid collection over the following two days was seen, she was discharged home with a close outpatient follow-up.

FNA and biopsy results were available six days later and revealed that approximately $29 \%$ of lymphocytes contained a monoclonal B cell lymphoid population with intermediate to large cell size with lambda 


\section{Cureus}

immunoglobulin light chain restriction. Results of flow cytometry and fluorescent in situ hybridization (FISH) study are provided in Table 2.

\begin{tabular}{|l|l|}
\hline Markers present & Markers absent \\
\hline CD45 & CD5 \\
CD19 & CD23 \\
CD20 & \\
CD10 & \\
CD38 & \\
\hline FMC7 & \\
\hline Translocation present & Translocation absent \\
\hline Translocation $14 ; 18$ in $41 \%$ of the cells & BCL-6 and MYC gene \\
\hline
\end{tabular}

\section{TABLE 2: Flow cytometry and FISH results}

B-cell lymphoma-6 (BCL-6); fluorescent in situ hybridization (FISH)

On the basis of clinical features and biopsy results, a diagnosis of stage IV follicular lymphoma was made, and she was scheduled to follow up with oncology as an outpatient for further management.

\section{Discussion}

\section{Epidemiology and etiology}

Both chylothorax and chylous ascites are rare clinical entities defined by the presence of lymphatic fluid in the pleural and peritoneal cavities, respectively. A retrospective study done at Mayo Clinic, Rochester, in 2005 revealed a total of only 203 cases of chylothorax in the past 21 years with lymphomas being an important cause of nontraumatic chylothorax [1]. In a large collective study by Aalami et al. in 2000, the most common etiologies for chylous ascites included lymphomas and cirrhosis, which accounted for over two-thirds of their studied patients [2-3]. Figure 4, adapted from [1], lists important causes of chylothorax.

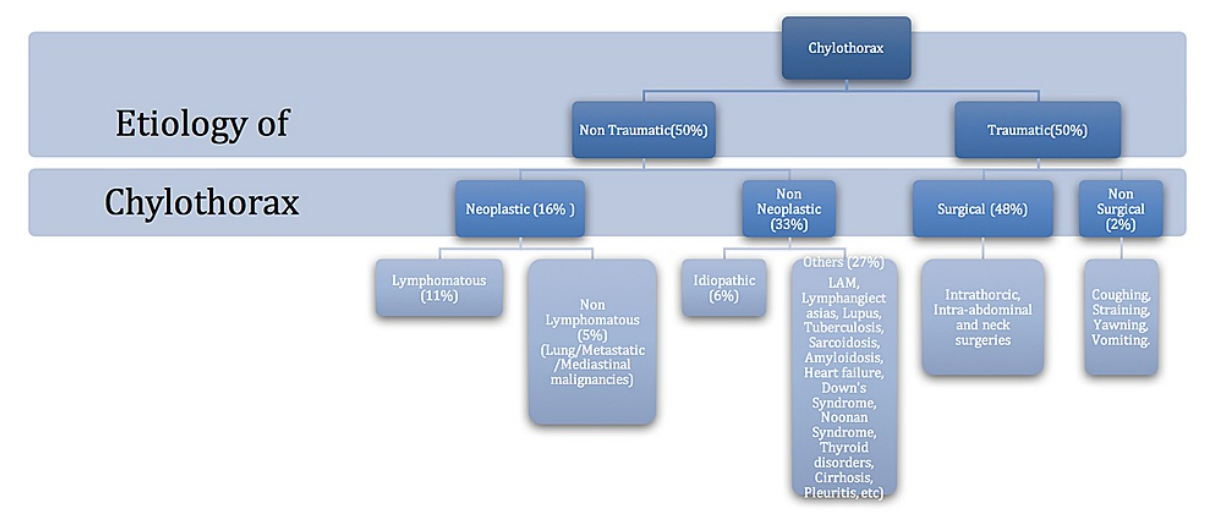

FIGURE 4: Etiology of chylothorax

Source: [1]

Pathogenesis 


\section{Cureus}

In a healthy adult, the thoracic duct transports 1.5 to $4 \mathrm{~L}$ of chyle daily, and its obstruction can cause leakage of chyle through lymphoperitoneal fistulae or leakage through dilated subserosal lymphatics into the peritoneal cavity [4]. The normal lymphatic system is depicted in Figure 5. In our patient, direct invasion of the cisterna chyli by the abdominal mass leading to chylous exudation into the peritoneum and further tracking up of this exudate across the diaphragm via diaphragmatic defects causing bilateral chylothorax seems to be the plausible mechanism.

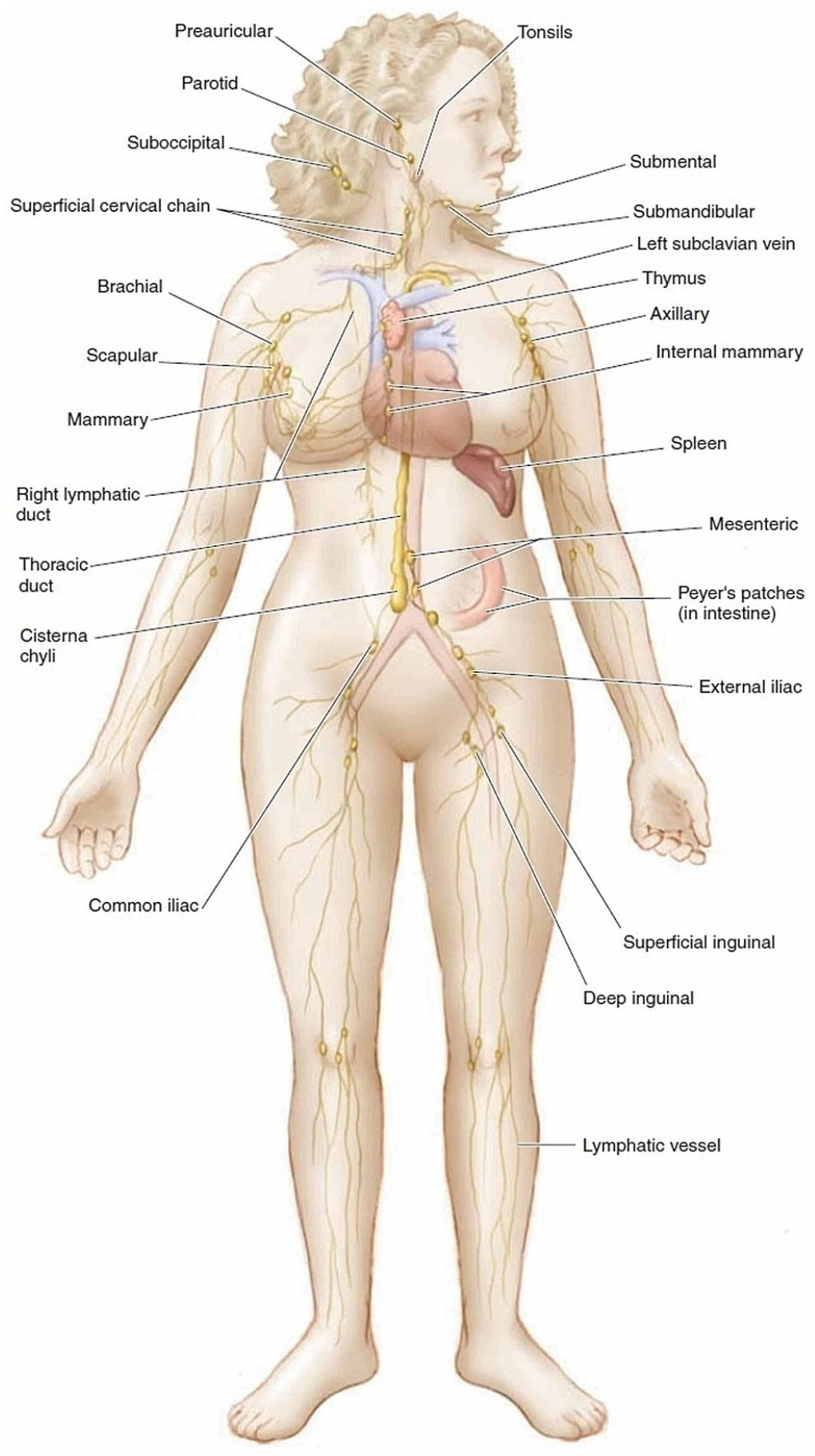

FIGURE 5: Normal lymphatic drainage

Source: [5]

\section{Diagnosis}

For the diagnosis of this condition, thoracentesis and paracentesis with fluid analysis remain the most important tools. Chyle has typically been described as a whitish exudate with a "milky," cloudy appearance 
due to its high triglyceride content. However, Staats et al. in 1980 [6] and Maldonado et al. in 2009 [7] demonstrated that less than $50 \%$ of chylous pleural effusions (proved by lipoprotein analysis) had this characteristic appearance with the majority being serous and serosanguinous in appearance. This emphasizes the importance of obtaining triglyceride and cholesterol levels in all pleural effusions of undetermined causes regardless of appearance [6-7]. Triglyceride values greater than $110 \mathrm{mg} / \mathrm{dL}$ are highly suggestive of chylous effusion, whereas levels less than $50 \mathrm{mg} / \mathrm{dL}$ are unlikely to be chylous effusions. Equivocal cases between 50 and $110 \mathrm{mg} / \mathrm{dL}$ require lipoprotein analysis for the demonstration of chylomicrons [8]. Maldonado et al. also noted that a majority (86\%) of these effusions were exudative due to the pleural fluid: serum protein ratio being more than 0.5 . The occasional transudative chylous effusions were most commonly seen with ascites. In all the chylous effusions in this study, LDH levels were usually in the transudative range, which is in contrast to our patient with an LDH of $345 \mathrm{U} / \mathrm{L}$, likely due to her large midabdominal follicular lymphoma. Most chylous effusions are lymphocyte-predominant due to the presence of $\mathrm{T}$ lymphocytes in the lymph while neutrophil predominance is mostly seen in post-surgical cases or in association with intraperitoneal infections [7]. Our patient's pleural effusion on tapping had a characteristic whitish milky appearance with a triglyceride level of $965 \mathrm{mg} / \mathrm{dL}$ and lymphocytic predominance.

\section{Management}

The management strategies and prognosis for chylous ascites and pleural effusions largely depend on the underlying etiology, and a wide variation in resolution rates has been noted. Conservative management with a high-protein and low-fat diet, which is rich in MCTs, is recommended since MCTs are absorbed by the intestinal cells and transferred as free fatty acids (FFA) and glycerol directly to the liver via the portal vein with no involvement of the thoracic duct, thereby decreasing the volume of chyle. However, MCT supplementation is contraindicated in patients with advanced cirrhosis due to the high risk of narcosis and subsequent coma [9]. Repeated peritoneal and pleural taps, along with chest tube drainage, are often needed for symptomatic treatment.

In 2006, Roehr et al. reported a study describing the use of somatostatin and octreotide drips for the management of chylothorax in 35 children. This approach is often combined with fasting and total parenteral nutrition (TPN) as a second-line treatment in case of the failure of conservative management [10]. Maldonado et al., in a retrospective study of 74 patients, noted that conservative management was successful for $49 \%$ of patients with traumatic chylothorax but only $27 \%$ in nontraumatic chylothorax [11]. In such cases, surgical modalities, including thoracic duct ligation or embolization, remain the last line of defense and might actually be preferred in patients with especially large drainage of more than a liter in a day.

Our patient had very slowly enlarging chylous ascites and effusion, which were easily managed with therapeutic thoracentesis, paracentesis, and dietary modifications. She was referred to oncology for definitive treatment of her follicular lymphoma.

\section{Conclusions}

Chylothorax and chylous ascites are rare clinical entities, and lymphoma is the most common nontraumatic etiology for both and should be ruled out in these patients. Gross inspection of the pleural and peritoneal fluid is the first clue in diagnosis but can often be misleading. Hence, chemical analysis of pleural fluid and ascites of unknown etiology should always include triglyceride levels. Lipoprotein analysis should be considered for triglycerides between the range of 50 to $110 \mathrm{mg} / \mathrm{dL}$. A trial of conservative management with dietary changes should be given before proceeding to more invasive procedures, especially in nontraumatic cases with a slow rate of re-accumulation.

\section{Additional Information}

\section{Disclosures}

Human subjects: Consent was obtained or waived by all participants in this study. Conflicts of interest: In compliance with the ICMJE uniform disclosure form, all authors declare the following: Payment/services info: All authors have declared that no financial support was received from any organization for the submitted work. Financial relationships: All authors have declared that they have no financial relationships at present or within the previous three years with any organizations that might have an interest in the submitted work. Other relationships: All authors have declared that there are no other relationships or activities that could appear to have influenced the submitted work.

\section{References}

1. Doerr CH, Allen MS, Nichols FC, Ryu JH: Etiology of chylothorax in 203 patients . Mayo Clin Proc. 2005, 80:867-870. 10.4065/80.7.867

2. Press OW: Evaluation and management of chylous ascites . Ann Intern Med. 1982, 96:358-364. 10.7326/0003-4819-96-3-358

3. Aalami OO, Allen DB, Organ CH Jr: Chylous ascites: a collective review . Surgery. 2000, 128:761-778. 


\section{Cureus}

10.1067/msy.2000.109502

4. Browse NL, Wilson NM, Russo F, Al-Hassan H, Allen DR: Aetiology and treatment of chylous ascites . Br J Surg. 1992, 79:1145-1150. 10.1002/bjs.1800791110

5. Drainage route of lymph. Accessed: March 20, 2021: http://www.brainkart.com/article/Drainage-Route-ofLymph_21098/.

6. Staats BA, Ellefson RD, Budahn LL, Dines DE, Prakash UB, Offord K: The lipoprotein profile of chylous and nonchylous pleural effusions. Mayo Clin Proc. 1980, 55:700-704.

7. Maldonado F, Hawkins FJ, Daniels CE, Doerr CH, Decker PA, Ryu JH: Pleural fluid characteristics of chylothorax. Mayo Clin Proc. 2009, 84:129-133. 10.4065/84.2.129

8. Skouras V, Kalomenidis I: Chylothorax: diagnostic approach. Curr Opin Pulm Med. 2010, 16:387-393. 10.1097/mcp.0b013e328338dde2

9. Laterre PF, Dugernier T, Reynaert MS: Chylous ascites: diagnosis, causes and treatment . Acta Gastroenterol Belg. 2000, 63:260-263.

10. Roehr CC, Jung A, Proquitté H, Blankenstein O, Hammer H, Lakhoo K, Wauer RR: Somatostatin or octreotide as treatment options for chylothorax in young children: a systematic review. Intensive Care Med. 2006, 32:650-657. 10.1007/s00134-006-0114-9

11. Maldonado F, Cartin-Ceba R, Hawkins FJ, Ryu JH: Medical and surgical management of chylothorax and associated outcomes. Am J Med Sci. 2010, 339:314-318. 10.1097/maj.0b013e3181cdcd6c 